References

Primrose, D. A. (1974) The changing pattern of admissions to a mental deficiency hospital. Health Bulletin. 32, No. 5, 1-3.

(1984) Changing sociological and clinical patterns in mental handicap. British Journal of Psychiatry, 144, 1-8.

\section{Down's Syndrome with Mania}

SIR: Please permit me to make some comments on Cook \& Leventhal's letter (Journal, May 1988, 152, 721-722) in response to my previous letter (Journal, March 1988, 152, 436-437).

Firstly, while I agree with them that developmental considerations per se might modify the clinical presentation of psychiatric illness, this is mainly in the area of symptomatology requiring the use of language. The biological features, such as altered appetite, altered sleep, and restless overactivity, are not affected as demonstrated by cases of mania associated with other conditions of mental retardation. In my own practice I have treated full-blown manic cases in the setting of mental retardation due to other causes. Even in Down's syndrome of borderline intelligence I have not come across manic illness. I do not believe the altered picture in Down's syndrome is solely due to developmental delays.

Secondly, the post-mortem studies, although limited, do point towards noradrenergic cell loss even in younger Down's syndrome cases (Mann et al, 1985). This, in association with clinical experience and epidemiological study (Singh \& Zolese, 1986), is suggestive of association between Down's syndrome and lack of mania.

Thirdly, in their letter Drs Cook \& Leventhal seem to be retracting from their original statement. In the original article (Journal, February 1987, 150, 249 $250)$ they wrote, "In fact a case can be made for a heightened association of Down's syndrome and bipolar affective illness". They go on to quote the Prange et al (1974) hypothesis.

Finally, I agree with Drs Cook \& Levanthal that further epidemiological and neurochemical information is required to help clarify the situation.

IQBAL SINGH

Leavesden Hospital

College Road

Abbots Langley

Herts WDS ONU

\section{References}

Mann, D. M. A., Yates, P. O., Marcynuik, B. \& RAvindra, C. R. (1985) Pathological evidence for neurotransmitter deficits in Down's syndrome of middle age. Journal of Mental Deficiency Research, 29, 125-135.

Prange, A. J., Wilson, I. C., LynN, C. W. et al (1974) Tryptophan in mania. Archives of General Psychiatry, 30, 56-62.
SINGH, I. \& ZOLESE, G. (1986) Is mania really incompatible with Down's syndrome? British Journal of Psychiatry, 148, 613-614.

\section{Dangerous Delusions: The 'Hollywood Phenomenon'}

SiR: Shubsachs \& Young (Journal, May 1988, 152, 722), in reporting two cases of a variant of a delusional misidentification syndrome which they have termed the 'Hollywood phenomenon', expressed the view that this symptom was under-reported and not specific for affective disorders. We here report an example of this symptom occurring in a paranoid schizophrenic patient. As in one of their cases, the symptom was directly associated with violence to others.

Case report: GW, A 23-year-old unemployed man with a history of a previous admission for an acute schizophrenic psychosis, was remanded in custody on charges of malicious wounding, burglary, and possession of an offensive weapon. For 5 months he had felt that he was being filmed by hidden cameras and that newspaper articles had a special significance for him. He believed that people spoke to him in codes. Prior to the offence he had not slept and felt "high and excited". He felt that he was performing theatre, that he had been hypnotised and that codes had been put into his mind. On the night of the offences he smashed windows, believing it was part of the filming exercise. He defecated in a bin, returned to his flat, and cooked some stew. He left the flat in stockinged feet and festooned three young men with the stew. The men withdrew. He felt compelled to ring a doorbell which said "this one". A young man answered and GW entered, claiming to be a member of the Drug Squad. He ransacked the flat, played a guitar, picked up a Stanley knife, and made the two male occupants take off their trousers. He cut one of the occupants on the arm. He made them walk to a telephone box, and in the process cut the other man on his back. He made the men telephone the police, who arrived and arrested $G W$ when he claimed to be a member of the Drug Squad, was abusive and attempted to drive the police car.

When seen in custody and after admission he maintained that the staff and the interviewing doctor were members of the SAS. He had ideas of reference and passivity feelings. He believed that the sequence of events was part of an SAS training exercise which was being filmed.

Physical examination and investigations were unremarkable. The patient responded well to treatment, but insight never fully returned. In informal out-patient follow-up he insisted on stopping his medication and relapsed within 3 months. His symptoms on readmission were similar to his earlier presentation, but without a recrudescence of the 'Hollywood phenomenon' and without violence to others.

This case suggests that the 'Hollywood phenomenon' is not specific to affective disorders. There is a possibility that the episode was precipitated by amphetamine abuse, although a urine sample was not obtained during his remand in custody and the patient 
gave a conflicting history. However, his response to treatment and the subsequent course of his condition rule out a simple drug-induced psychosis, and our favoured diagnosis is paranoid schizophrenia.

Fish's Clinical Psychopathology (Hamilton, 1974) asserts that delusional ideas, in contrast to overvalued ideas, are not commonly acted upon. Our case, together with those of Drs Shubsachs \& Young and Drs de Pauw \& Szulecka (Journal, January 1988 , 152, 91-97), suggests that, in delusional misidentification syndromes at least, this assertion needs to be treated with as much caution as the patients!

A. R. TOMison

Butler Clinic W. M. DONOVAN

Langdon Hospital

Exeter Road

Dawlish EX7 0NR

Reference

Hamilton, M. (1974) Fish's Clinical Psychopathology. Bristol: John Wright \& Sons.

\section{Response to Biological Treatment}

SIR: As a clinical biochemist working in psychiatry, the article by Myers (Journal, May 1988, 152, 657659) on the prediction of response of depressed patients to treatment provokes me to a comment. Not on the design or results of the study, which are interesting enough, but on a more than purely semantic problem.

Because biological psychiatry studies biochemistry, physiology, anatomy, etc. in relation to psychiatric disorders, and because pharmacological findings do considerably contribute to the increase of knowledge in biological psychiatry, this does not imply that applied psychopharmacology, i.e. drug treatment, in psychiatry is a biological treatment.

The generally accepted meaning of the word 'biological' implies a relation to the science of life or to life processes and phenomena. I sincerely hope we may prevent a deterioration of the sense of the term 'biological' analogous to that of the term 'chemical' to mean synthetic or artificial. Calling the use of antidepressant drugs a 'biological' treatment is more than confusing. Why not 'drug' or 'pharmacological' treatment? In this respect it may even be maintained that psychotherapy, for example, is a more biological treatment than the use of drugs.

G. M. J. VAN KEMPEN

Psychiatric Hospital Endegeest

POB 1250

2340 BG Oegstgeest

The Netherlands

\section{The Pathogenesis of Depersonalisation}

SIR: Before Professor Cohen's suggestion of a causal link between hyperventilation and depersonalisation becomes universally "received knowledge" (Journal, April 1988, 152, 578), it would be helpful to know what were his criteria for diagnosing hyperventilation, and whether the traditional brown paper bag is effective in depersonalisation.

In my experience, when the two conditions co-exist the anxiety is the result of the experience of depersonalisation and the latter is often of such abrupt onset that it would be hard to explain it in biochemical terms related to overbreathing. Moreover, a positive understanding of the personal meaning of the symptom can often be acquired through patient self-monitoring (Ryle, 1982), as the following two cases illustrate.

Case reports: (i) A young man experienced intense depersonalisation at the railway station after a visit to his mother. Since his father's death 5 years previously he had felt overinvolved with his mother, and visits were marked by a mutual exacerbation of depression and psychosomatic symptoms. His attack had generated panic and the fear of going mad. Self-monitoring of subsequent attacks revealed that all occurred as an immediate consequence of a thought, event, or another's remark implying the possibility that he might be sexually potent, or, on one occasion, followed him seeing himself in the barber's mirror and thinking "Macbeth, Lear, Oedipus". In psychoanalytic terms, therefore, his depersonalisation (aptly named) removed him from the possibility of profiting from his 'oedipal victory' over his father.

(ii) A 25-year-old man had suffered for 2 years from severe depression with numerous suicide attempts. Over this period he had been increasingly disabled by intense and frequent depersonalisation experiences. His older sibling had been a furious child and had become schizophrenic during adolescence. $\mathrm{He}$, in contrast, had been a compliant, high-achieving but emotionally cut-off person. Selfmonitoring of his depersonalisation showed it to be provoked by feeling controlled or misunderstood, and he was able to recognise a flash of anger prior to the onset of the symptom. In this case also, the symptom can be seen to prevent the patient becoming the kind of person who, for reasons of his history, was unacceptable.

Depersonalisation should be considered in terms of its personal meaning to the sufferer; surely Professor Cohen is not suggesting that all disorders of perception have an organic base?

York Clinic and Munro Clinic

ANTHONY RYLE Guy's Hospital

London Bridge SE1 9RT

\section{Reference}

RYLE, A. (1982) Psychotherapy: A Cognitive Integration of Theory and Practice. London: Academic Press. 